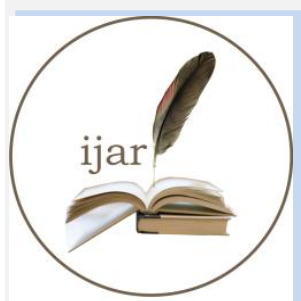

ISSN NO. $2320-5407$
Journal Homepage: $-\underline{w w}$.journalijar.com
INTERNATIONAL JOURNAL OF
ADVANCED RESEARCH (IJAR)

Article DOI: $10.21474 / \mathrm{IJAR01/1538}$

DOI URL: http://dx.doi.org/10.21474/IJAR01/1538
INTERNATIONAL JOURNAL OF ADVANCED RESEARCH (JJAR)

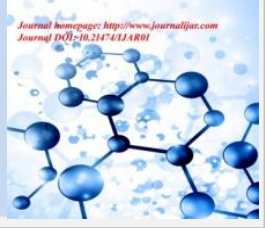

RESEARCH ARTICLE

\title{
ROLE OF FEMALE LITERACY AS A MEANS TO IMPROVED CHILD HEALTH IN ASSAM
}

\author{
Dipali Baishya.
}

Research student, Department of Economics, Gauhati University.

\section{Manuscript Info}

\section{Manuscript History}

Received: 15 July 2016

Final Accepted: 16 August 2016

Published: September 2016

Key words:-

Infant Mortality Rate, Education, Female literacy.
Abstract

The health status of a country is reflected in the Infant Mortality Rate of the country. In fact it is one of the most pertinent problems facing the developing nations. Well integrated efforts are being made by the Governments worldwide to reduce the Infant Mortality Rate. The factor which plays a poignant role in IMR reduction is the education of the mother. This paper studies the important role of female education in lowering the infant mortality rates in Assam and the steps taken by the Government of Assam in educating the female population.

Copy Right, IJAR, 2016, All rights reserved.

\section{Introduction:-}

Infant mortality is the deaths of young children, typically those less than one year of age. It is measured by the infant mortality rate (IMR), which is the number of deaths of children under one year of age per 1000 live births. ${ }^{[1]}$

Infant Mortality is an indicator of the health status of the country. The infant mortality rate of the world is 49.4 according to the United Nations and 42.09 according to the CIA World Fact book. The under-5 mortality rate of the world is 73.7 according to the United Nations. ${ }^{[2]}$

The causes of high infant mortality are the following: Birth related Causes, Standard of living, lack of education, non availability of medical treatment facilities and legitimacy. ${ }^{[3]}$ Birth related causes are those causes which are responsible for neonatal death like death due to birth before maturity period of pregnancy, deformity, birth wounds, suffocation and lack of timely medical care. Standard of living and infant mortality are mutually dependent. Parents with higher income can bring up their children in a better way. In other words as the level of economic condition improves infant mortality decreases. Mortality rates also depend on the education level of the parents. Educated parents provide nourishing diet to their children, give them the best available medical care during illness and immunize them against diseases through control devices.

${ }^{[1]}$ https://en.wikipedia.org/wiki/Infant_mortality

${ }^{[2]} \mathrm{https} / / /$ en.wikipedia.org/wiki/List_of_countries_by_infant_mortality_rate

${ }^{[3]}$ Sinha,V.C and Zacharia, E.,'Elements of Demography"

${ }^{[4]} \mathrm{https} / / /$ data.gov.in/keywords/infant-mortality-rate 
Again, the death rate is less in those places where medical facilities are available without much difficulty. Proper medical care can check the spread of child diseases and timely medical care can control the diseases in the initial period. Also infant mortality is high in illegitimate children born out of the wedlock. Death is comparatively less in children born out of legitimate birth. Society looks down on illegitimately born children and their mothers. This tendency to do away with illegitimate children is another reason for high infant mortality. The current Infant Mortality Rate of India, as per the Sample Registration System 2013, is 40 per 1,000 live births while the Under-5 Mortality Rate as per SRS 2012 is 52 per 1,000 live births. ${ }^{[4]}$ The health of a nation is reflected in its children. Thus Infant mortality is one of the most pertinent problems facing India at large and Assam in particular.

\section{Objective:-}

To study the ways in which female literacy can help in reduction of Infant Mortality rate in Assam.

\section{Materials and Method:-}

The present work is entirely theoretical and hence is based on literature review only.

\section{Literature review:-}

Papageorgiou, C. and Stoytcheva, P. (2008) has examined the relationship between female human capital inequality and Infant mortality and showed that higher education inequality among women, measured by Gini Coefficient, leads to substantially higher infant mortality. Thus it was concluded that if Infant mortality reduction is a priority for policy makers then educating the least educated women first seems to be an effective and also simple policy recommendation.

Boehmer, U and Williamson, J.B in their study has presented an inverse relationship between the status of women and infant mortality rate. It shows that in addition to women's educational status, other dimensions of women's status particularly economic status and autonomy are also important predictors of Infant Mortality Rate.

Choudhury, P.K. (2013) has found that the children born to mothers having any kind of exposure to the mass media have lower probability of death in their infant stage compared to the children born to the mothers having no mass media exposure. The findings suggest that the low level of female education is a major hindrance to reduce the infant deaths in rural India. The policy implications of the study include providing education to the parents particularly to the mother's of backward regions or states. Besides parent's education attempt should be made to increase the scope of getting mass media exposure and higher level of socio-economic empowerment of the mother to reduce infant mortality rates in India.

Abuqamar, M., Coomans, D. And Louckx, F. (2011) has concluded that families with lower educational level had a much higher risk of Infant mortality. Thus there was a positive statistical association between parental education and survival of infants.

Caldwell, J. and McDonald, P. has concluded that parental education is important though not as important as maternal education and the step from primary to secondary schooling is more important than that from illiteracy to primary schooling.

Pena, R.,Wall, S. and Pearson, L.A., has concluded that apart from absolute level of poverty, social inequality may be an important risk factor for infant mortality in a low income country. In poor households, female education may contribute to preventing infant mortality.

Caldwell, J.C. has shown from the analysis of Nigerian statistics that very different levels of child survivorship result from different levels of maternal education in an otherwise similar socio-economic context and when there is equal access to the use of medical facilities. Indeed, maternal education in Nigeria appears to be the single most powerful determinant of the level of child mortality.

Lindenbaum, S., Chakraborty, M and Elias, M. indicates that the lives of educated women differ from those of uneducated women in a number of ways that may affect the survival chances of their infants and children. Education raises a women's age of first marriage, protecting her from the risk of infant mortality associated with child bearing at a very young age. 
Thus from the above literature it is very much evident that education of the mother is the most important factor to have a bearing on infant mortality. Taking this aspect into consideration the Government of Assam has launched numerous schemes to improve female literacy. The main strategies adopted by the Government for increasing female literacy in the country include:

1. National Literacy Mission for imparting functional literacy

2. Universalization of Elementary Education

3. Non-Formal Education

The result of the strategies adopted by the government is highlighted through the rise in the female literacy rate in Assam

Table 1:- Female literacy rate of Assam and India (1951-2011)

\begin{tabular}{|l|l|l|}
\hline Year & Assam & India \\
\hline 1951 & 7.58 & 8.66 \\
\hline 1961 & 18.62 & 15.35 \\
\hline 1971 & 22.76 & 21.97 \\
\hline 1981 & - & 29.76 \\
\hline 1991 & 43.03 & 39.29 \\
\hline 2001 & 54.61 & 53.67 \\
\hline 2011 & 66.27 & 64.64 \\
\hline
\end{tabular}

Source: Statistical Handbook -Assam 2013

From the above table it is seen that the literacy rate of Assam was 7.58 in Assam and 8.66 in the year 1951. From then onwards it is seen that the female literacy rate of Assam is always greater than the all India rates. Hence it can be said that the Government of Assam has achieved a lot of progress in terms of female literacy.

Along with increasing literacy steps have also been taken to lower the infant mortality rates in Assam. The various schemes launched by the Government of Assam for reduction of IMR are:

Mamata - The 'Mamata' scheme seeks to reduce IMR and MMR, by insisting on a post-delivery hospital stay of 48 hours of the mother and the newborn. Any complications arising during this period is addressed by skilled doctors available at Government health institutions. During discharge from the hospital, the mother is given a 'Mamata' kit. This kit contains essential products for the baby viz. baby powder, baby oil, a mosquito net, a flannel cloth etc. After 48 hours of stay in government hospital, the 'Mamata kit' is given to the mother. Till date 10, 01,923 'Mamta kit' has been distributed since 2010-11 to 2013-14.

Mamoni - This scheme provides Cash assistance to Pregnant Women for Nutritional support @ Rs. 1000/- in two installments. "Mamoni" is a scheme of the Government of Assam that encourages pregnant women to undergo at least 3 ante-natal checkups (ANC) which identify danger signs during pregnancy (needing treatment) and offer proper medical care. Under this scheme, at the time of registration, every pregnant woman receives a booklet on tips on safe motherhood and newborn care titled 'Mamoni'. During subsequent ANC check up, the pregnant women are provided with an amount of Rs. 1000 (in two installments, first for 2nd ANC an amount of Rs. 500/- is given and second installment of Rs. 500/- for 3rd ANC as nutritional support) for expenses related to nutritional food and supplements. Every Government health institution offers these services for the women who have registered in their place. It is under "Assam Bikash Yojana", State Government sponsored schemes under Health \& Family Welfare Department. Till 20013-14, total 36, 50,453 numbers of cheques has been disbursed.

Majoni- Under this scheme social assistance is provided to all girl children born in the family up to second order. Each girl child is given a fixed deposit of Rs. 5,000/- for 18 years. On her 18th Birthday, the girl will be able to encash the fixed deposit. In case she is married before attaining 18 years of age, the fixed deposit will be forfeited. This Scheme is applicable to families who are limiting themselves to two children. It is under Assam Bikash Yojana (ABY) State Government sponsored schemes under Health \& Family Welfare Department. Till 2013-14, total 3, 08,109 numbers of Fix Deposit has been issued (Source: ABY Report)

Morom - Financial Support is provided to Indoor Patients of Government Hospitals 
The Morom scheme provides financial support to indoor patients of Government Health Institutions for supplementary nutrition and compensation for wage loss during hospitalization and post hospital expenses. The facility is available for Indoor Patient admitted in Government Hospitals. Indoor patients admitted to a Hospital will receive benefit as follows:

* For Medical College: Rs. 75/- per day for maximum 7days

* For District Hospital: Rs. 50/- per day for maximum 5days

* For SDCH/ CHC/ PHC: Rs. 30/- per day for maximum 5days.

The scheme is effective from 1st May 2010. It is a Government. of Assam sponsored scheme. Amount paid under Morom scheme till 2013-14 is Rs.2061.66 Lakhs. ${ }^{[5]}$ The Government of Assam has made all out efforts to lower the infant mortality rates through incentives, institutionalization of deliveries etc. But all these schemes will be fruitful only when the mothers are educated. Education is important to avail these benefits offered by the government. It is only through education that women can have exposure to the various schemes launched by the government from time to time for the benefit of mothers (pregnant women) as well as infants. Education provides a way of life to the people. Mothers can take proper care of the infants, give them the required nutrition. Besides Education helps the mother to know how she needs to take care of herself so that the mother and the infant stays healthy. Educated women prefer small size of the family with proper awareness about the methods of contraception. A healthy gap between children ensures a healthy pregnancy. Fewer children in a family increase the chances that an infant will survive. Education helps women to take better pre natal care and also proper immunization of the infant against various diseases.

In Assam as per the SRS (December, 2011), Infant Mortality Rate (IMR) in Assam (2010) is 58 per 1000 live births against 47 for the country as a whole. Thus the IMR has improved considerably during 2000-2011. In 2000, the IMR for the state was 74.5 against the all India figure of 67.8. There has, therefore, been an improvement by 22 percent in Assam vis-à-vis 30 percent for the country. This improvement is due to continuous and multipronged initiatives of the government. Despite a marginal reduction in the Infant Mortality Rate (IMR) (by 3 points) from 61 per 1,000 live births (2009) to 58 per 1,000 live births (2010), Assam continues to rank among the four highest IMR States in the country, next only to Madhya Pradesh (62 per 1,000 live births), Uttar Pradesh and Orissa (61 per 1,000 live births), and far higher than the national average of 47 per 1,000 live births. Within the North East region, all the other States have better IMR as compared to Assam. Besides, the IMR in Assam is worryingly biased towards the rural and female population which indicates that if you are a girl infant in the rural areas, your chances of survival beyond the age of one year is much lower than your male or urban counterpart. Moreover, the Neonatal Mortality Rate (NNMR), i.e. the number of infant deaths in less than 28 days of birth for Assam is 33 per 1,000 live births in 2009 which indicates that, of the total infant deaths in the State, 54.7 per cent take place within the first 28 days of birth. The under-5 Mortality Rate (U5MR) in Assam is 87/1,000 live births in 2009, as compared to the all India figure of 64. Here again, the bias against the girl child with Assam recording 91 per 1,000 live births, which is one of the highest in the country. It is, therefore, imperative that the IMR should be reduced at a much faster pace i.e. at least two third of the present rate, with a special emphasis on rural and girl child, so that life expectancy as well as overall human development index improves. [6]

\section{Conclusion:-}

Thus it is seen that Assam has come a long way in terms of Infant mortality rate reduction from 80 per 1000 live births in 1990 to 58 in 2010. But it is still below the national IMR. Hence a lot of ground needs to be covered. In addition, the matter which needs utmost attention is the removal of gender biasedness which is very much prevalent in the villages of Assam. The desire for a male child leads to numerous pregnancies thereby endangering the lives of both the mother and the child. Hence it is only when the light of education percolates down to the rural household level that a healthy society with gender equality can be achieved.

${ }^{[5][6]}$ Assam Government Schemes, 2014. 


\section{References:-}

1. https://en.wikipedia.org/wiki/Infant_mortality

2. Infant and Child Mortality in India -Levels trends and determinants: UNICEF Report.

3. Papageorgiou, C. and Stoytcheva, P.," Education Inequality among Women and Infant Mortality: A cross country empirical investigation," April 2008.

4. 4. Boehmer, U. and Williamson, J.B.," The impact of Women's status on Infant Mortality Rate: A cross national analysis.

5. Choudhury, P.K.,' Parental Education and Infant Mortality in India: Understanding the Regional Differences, ISID-PHFI Collaborative Research Programme, Working Paper-157, November, 2013.

6. Abuqamar, M., Coomans, D. and Louckx,F.," The impact of Parental education and Infant Mortality in Gaza Strip, Palestine.” Journal of Public Health and Epidemiology, Volume 3(1), Pp 28-33, January, 2011.

7. Caldwell, J. and McDonald, P., "Influence of maternal education on infant and child mortality: Levels and Causes." Health Policy and Education, Volume-2, Issue 3-4, Pp 251-267, March 1982.

8. Pena, R., Wall, S., and Persson, L.A.," The effect of Poverty, social inequity and maternal health on infant mortality in Nicaragua." American Journal of Public Health, Volume 90(1) Pp 64-69, January 2000.

9. Caldwell, J.C.," Education as a factor in Mortality Decline- An examination of Nigerian Data." Population Studies, Volume 33 Number 3, Pp 395-413, November, 1979.

10. Lindenbaum, S., Chakraborty, M., and Elias, M.," The influence of Maternal Education on infant and child mortality in Bangladesh.” International centre for Diarrhoeal Disease Research Special Publication No 23.

11. Sinha, V.C and Zacharia, E.,'Elements of Demography", Allied Publishers Private Limited. 